\title{
Synthesis and Application Areas of Heteropolyacid Intercalated Clays as Novel Acid Catalysts
}

\section{Chandra Mohan* and Vinod Kumar}

Department of Chemistry, KR Mangalam University, India

*Corresponding author: Chandra Mohan, Department of Chemistry, KR Mangalam University, Gurgaon 122103, Haryana, India, Email: chandra.mohan@krmangalam.edu.in

Keywords: Heteropoly acid; Clay; HPA intercalated clay

Abbreviations: HPA: Heteropoly Acids; STA: Silicotungstic Acid; PTA: Phosphotungstic Acid; SMA: Silicomolybdic Acid; PMA: Phosphomolybdic Acid.

\section{Introduction}

A heteropoly acid (HPA) is made up of a particular combination of hydrogen and oxygen with certain metals and non-metals. In past years, Heteropoly acids have been extensively studied as acid catalysts for many reactions and found industrial applications on large scale. HPAs have several advantages over mineral acid catalysts, including non-corrosive and environmentally benign in nature. Use of heteropoly acids (HPAs) in heterogeneous acid catalysis has the significance of substantial economic and green benefits.

Heteropoly catalysts are used in wide variety and high potential, because HPAs have significantly higher catalytic activity than mineral acids. HPA intercalated clay have proved to be very efficient catalyst. Clays are layered aluminosilicates held together by weak forces [1]. That's why intercalation of clays via exchange of interlayer cation with metal ions with thermal treatment is a useful technique to obtain catalysts. Clays are widespread, easily available and low-cost chemical substances [2-4].

Clay as a catalyst is environmentally benign, recyclable and economical, and there is a need to replace the conventional catalysts. For the modification, we have synthesized a series of HPA intercalated clays by using various HPAs such as Silicotungstic acid (STA),
Phosphotungstic acid (PTA), Silicomolybdic acid (SMA), Phosphomolybdic acid (PMA). These HPA intercalated clays can be used as catalysts for various types of organic reactions such as addition reactions, condensation reactions, Diels-Alder reactions, esterification reactions, Friedel-Crafts reactions, isomerization and oxidation reactions. By a simple method, HPAs intercalated clay can be synthesized and used as solid acid catalyst for coumarin derivatives with high efficiency and yield in a very short time [5-9].

\section{References}

1. Kaur N, Kishore D (2012) Montmorillonite: An efficient, heterogeneous and green catalyst for organic synthesis. J Chem Pharma Res 4(2): 9911015.

2. Mohan C, Kumari S (2015) Microwave Assisted Synthesis of Coumarins by Pechmann Reaction Using HPA Modified Clays as Catalysts. Int J Scient Res 4(10): 16-18.

3. Kozhevnikov IV (1987) Advances in Catalysis by Heteropolyacids. Russ Chem Rev 56(9): 811-825.

4. Hamdi N, Saoud M, Romerosa A, Hassen RB (2008) Synthesis, spectroscopic and antibacterial investigations of new hydroxy ethers and heterocyclic coumarin derivatives. J Heterocycl Chem 45(6): 18351842.

5. Kirkiacharian BS, Clercq E, Kurkjian R, Pannecouque C (2008) New synthesis and anti-HIV and antiviral properties of 3-arylsulfonyl derivatives of 4- 


\section{Medicinal \& Analytical Chemistry International Journal}

ydroxycoumarin and 4-hydroxyquinolone. J Pharm Chem 42: 265.

6. Surasani R, Kalita D, Rao AVD, Yarbagi K (2012) $\mathrm{FeF}_{3}$ as a novel catalyst for the synthesis of polyhydroquinoline derivatives via unsymmetrical Hantzsch reaction. J Fluorine Chem 135: 91-96.

7. Atar AB, Jeong YS, Jeong YT (2014) Iron fluoride: the most efficient catalyst for one-pot synthesis of $4 \mathrm{H}$ - pyrimido [2,1-b] benzothiazoles under solvent-free conditions. Tetrahedron 70(34): 5207-5213.

8. Valverde L, Canizares P, Sun Kou MR, Molina CB (2000) Enhanced Thermal Stability of Al-Pillared Smectites Modified with Ce and La. Clays and Clay Minerals 48(4): 424-432.

9. Chaudhari DA (1983) Chem Ind 568. 